\title{
QUALIDADE DA EDUCAÇÁO SUPERIOR NO BRASIL: DESEMPENHO DAS UNIVERSIDADES CATÓLICAS À LUZ DOS RANKINGS ACADÊMICOS, ÍNDICES E TABELAS CLASSIFICATÓRIAS ESTATAIS E DO SETOR PRIVADO ${ }^{1}$
}

\author{
QUALITY OF HIGHER EDUCATION IN BRAZIL: PERFORMANCE \\ OF CATHOLIC UNIVERSITIES IN THE LIGHT OF ACADEMIC \\ RANKINGS, STATE CLASSIFIED INDEXES AND TABLES
}

\begin{abstract}
Marco Wandercil
Doutor em Educação pela Pontifícia Universidade Católica de Campinas (PUC-CAMPINAS). Professor da Faculdade Santa Lúcia de Mogi Mirim. Mogi Mirim - São Paulo - Brasil. Especialista em Avaliação Institucional da PUC-Campinas. Campinas - São Paulo - Brasil. ORCID: https://orcid.org/0000-0002-9295-1051. marco.wandercil@gmail.com
\end{abstract}

Adolfo-Ignacio Calderón

Doutor em Ciências Sociais pela Pontifícia Universidade Católica de São Paulo (Brasil) com Pós-doutorado em Ciências da Educaçáo na Universidade de Coimbra (Portugal). Bolsista de Produtividade em Pesquisa do Conselho Nacional de Desenvolvimento Científico e Tecnológico (CNPq) do Brasil. Professor titular do Programa de Pós-Graduação em Educação da Pontifícia Universidade Católica de Campinas (PUC-CAMPINAS). Campinas - São Paulo - Brasil. ORCID: https://orcid.org/0000-0001-6534-2819 adolfo.ignacio@puc-campinas.edu.br

Francisco Aníbal Ganga-Contreras

Doutor em Gestão Estratégica pela Universidade de Sevilla (Espanha), com pós-doutorado em Ciências Humanas pela Universidad del Zulia (Venezuela). Professor titular do Departamento de Ciências do Desenvolvimento e diretor do Programa de Pesquisa sobre Governança e Inclusão Organizacional (PRIGO) da Universidade de Los Lagos, Chile. Osorno - Região de Los Lagos - Chile. ORCID: https://orcid.org/0000-0001-9325-6459 fganga@ulagos.cl

Resumo: A qualidade educação superior é um conceito dinâmico que tem que se adaptar a um mundo em constantes mudanças. Este artigo tem como objetivo analisar as universidades católicas brasileiras com o intuito de estudar suas tendências em termos de qualidade institucional, a partir da sua performance em rankings acadêmicos, índices e listas classificatórias (Rankintacs) nacionais em níveis estatal e privado. Para alcançar o objetivo deste estudo, realizou-se pesquisa bibliográfica-documental incluindo análise de indicadores de desempenho nos Rankintacs nacionais, incluindo análise qualitativa e quantitativas por meio de critérios estatísticos. Atualmente, o Brasil conta com 19 universidades confessionais católicas e seus desempenhos foram 
abordados a partir dos Rankings nacionais, elaborados pelo órgão regulador estatal (MEC/INEP) e os promovidos pelo setor privado, Ranking Universitário Folha (RUF) e Guia do Estudante. Embora tradicionalmente as universidades católicas sejam identificadas como instituiçóes de elevada qualidade, ocupando lugares de destaque entre as melhores universidades do país, muitas delas a frente de grandes universidades públicas, os Rankintacs revelam, em termos de qualidade, grande diversidade e heterogeneidade, existindo renomadas universidades católicas com resultados não tâo favoráveis, identificadas com fraco desempenho.

Palavra-chave: Rankings Acadêmicos. Qualidade da Educação. Universidades Católicas.

\begin{abstract}
Quality higher education is a dynamic concept that has to adapt to a changing world. This article aims to analyze the Brazilian Catholic universities in order to study their trends in terms of institutional quality, from their performance in national academic rankings, indexes and rankings (Rankintacs) at state and private levels. To achieve the objective of this study, a bibliographic-documentary research including analysis of performance indicators in national Rankintacs, including qualitative and quantitative analysis through statistical criteria was performed. Currently, Brazil has 19 Catholic confessional universities and their performances were approached from the National Rankings, prepared by the state regulatory agency (MEC/INEP) and those promoted by the private sector, Folha University Ranking (RUF) and Student Guide. Although Catholic universities have traditionally been identified as high quality institutions, occupying prominent positions among the best universities in the country, many of them ahead of large public universities, Rankintacs reveal in terms of quality, great diversity and heterogeneity, with renowned universities. Catholic with not so favorable results, identified with poor performance.
\end{abstract}

Keyword: Academic Ranking. Quality of education. Catholic universities.

\title{
Introduçáo
}

A qualidade na educação, ainda é um termo polêmico, pois permeia uma complexa arena de diversificados campos científicos, múltiplos modelos de estrutura institucional, de organização das atividades curriculares e de governança. Esta multiplicidade de fatores dificulta o estabelecimento de qualquer "padrão de qualidade", termo nascido com a administração científica, período em que as empresas passaram a "exercer o controle racional do trabalho humano, em busca de melhores resultados, de melhores índices de desempenho e de competitividade" (SANTANA, 2007, p. 19).

A qualidade por ser um termo polissêmico, sua aplicaçáo é complexa, pois a educação superior trata-se de um serviço que pode ser analisado por diferentes óticas, por exemplo, a ótica do mercado e da formação do 
cidadão e do profissional (SANTANA, 2007), podendo ser concebida de forma tanto instrumental (DEMING, 1990; ISHIKAWA, 1993) quanto crítica (DEMO, 1994; GENTILI, 1995).

Do ponto de vista instrumental, "refere-se a eficiência, controle e competitividade, base conceitual de um trabalho fundamentado em processos ou resultados ou uma estratégia de gestão que procura otimizar a produção e reduzir custos" (SANTANA, 2007, p. 20). Do ponto de vista da racionalidade crítica, questiona-se "o uso ideológico do termo qualidade em favor de uma visão particular de mundo, o capitalismo neoliberal, e procura desmascarar a ambiguidade nele presente" (SANTANA, 2007, p. 20).

A preocupação com o controle da qualidade da educação superior no Brasil surgiu na década de 1980, como forma de prestar contas à sociedade dos investimentos em educação efetuados pelo setor público (BRASIL, 2003), contexto em que surgiu o Programa de Avaliaçáo da Reforma Universitária (PARU) e, na década seguinte (1993), o Programa de Avaliação Institucional das Universidades Brasileiras (PAIUB) criado pela Secretaria de Educação Superior (SESu) do Ministério da Educação (MEC), de caráter formativo, processual e de adesão voluntária. No entanto, uma política de avaliação sistemática acontece em 1996, com o Exame Nacional de Curso (ENC) (BRASIL, 2003), substituído, em 2004, pelo Sistema Nacional de Avaliação da Educação Superior (SINAES). Apesar de uma concepção mais formativa de avaliação, o SINAES, com o tempo e com a inserção de novos indicadores de qualidade, acabou gerando listas classificatórias, estabelecendo um potencial elemento ranqueador das IES brasileiras, pois o próprio Ministério da Educação (MEC) começou a divulgar listas classificatórias.

Um aspecto que deve ser mencionado é que dentro do percurso da avaliação da educação brasileira, cada modelo avaliativo adotado apresenta especificidades em relação ao conceito de qualidade. Seja no PARU, no PAIUB, no ENC ou no SINAES, a questão da qualidade perpassa pela definição de critérios e indicadores de qualidade, com pesos e valoraçóes diferenciadas, não sendo os mesmos para os diversos modelos de avaliação.

Avaliar a qualidade da educação superior é uma prática já incorporada pelas Instituições de Educação Superior (IES) brasileiras, pois o 
SINAES tem exercido o papel de regulação. No entanto, outros mecanismos de aferição da qualidade passaram a adquirir destaque neste cenário, papel incorporado pelos rankings acadêmicos nacionais e internacionais. Altbach e Hazelkorn (2018) reconhecem os limites dos rankings acadêmicos e afirmam que

É impossível avaliar adequadamente a qualidade da educação para fins de comparaçóes internacionais, [...] avaliar o ensino e a aprendizagem é fundamental para determinar a qualidade do ensino superior, mas usar as metodologias atuais para produzir dados comparativos é imprudente, na melhor das hipóteses" (ALTBACH; HAZELKORN, 2018, p. 1)

Dada a heterogeneidade de metodologias presentes nos rankings, os "Princípios de Berlim para Rankings de Instituições de Educação Superior" reconhecem que boas práticas de classificação, são úteis para a melhoria e avaliação, tanto que um de seus objetivos e metas é de que os rankings sejam mais uma, entre várias abordagens de avaliação do ensino superior, pois os "rankings podem fornecer informaçóes comparativas e uma melhor compreensão do ensino superior, mas não devem ser o principal método para avaliar uma instituição de ensino superior" (IREG, 2006, p. 1).

Num cenário envolto de grandes mudanças e transformaçóes, neste estudo parte-se da premissa de que:

La calidad se ha convertido en un concepto dinámico que tiene que adaptarse permanentemente a un mundo cuyas sociedades experimentan hondas transformaciones sociales y económicas. Es cada vez más importante estimular la capacidad de previsión y anticipación. Ya no basta con los antiguos criterios de calidad. A pesar de las diferencias de contexto, existen muchos elementos comunes en la búsqueda de una educación de calidad que debería habilitar a todos, mujeres y hombres, para participar plenamente en la vida comunitaria y para ser también ciudadanos del mundo (UNESCO, 2001, p. 1. APUD MOROSINI, 2009, p. 172). 
Dentro desse contexto, analisar o desempenho das Universidades Católicas por meio de rankings acadêmicos implica em reconhecer que cada ranking, segundo Calderón (2019, p. 13), “tem objetivos diferentes [...] padronizando heterogêneas instituições educacionais, reduzindo a complexidade das atividades universitárias em alguns indicadores daquilo que pode ser mensurado".

Assim, este estudo tem como objetivo analisar as Universidades Católicas no Brasil (doravante denominadas, apenas de Católicas), com o intuito de estudar tendências em termos de qualidade institucional, a partir da suas performances em rankings acadêmicos, índices e listas classificatórias (Rankintacs) nacionais em nível estatal e privado. Parte-se da premissa de que é fundamental reconhecer essas especificidades dos rankings em termos da existência de diversas concepçóes de qualidade a partir das especificidades dos indicadores adotados, pesos e formas de coletas de dados para realizar leituras mais precisas das potencialidades ou fragilidades das Católicas à luz de diversos rankings acadêmicos.

Para alcançar o objetivo deste estudo, realizou-se pesquisa bibliográfica-documental incluindo análise quali-quantitativas de indicadores de desempenho nos Rankintacs nacionais, por meio de critérios estatísticos. Em termos da análise quantitativa e qualitativa de indicadores de desempenho das Católicas, considerando que são escassos os estudos envolvendo esse universo (CALDERON ET AL, 2011; LOURENÇO, 2014; ARDUINI, 2017), foram coletadas informaçôes nas bases de dados online do Ranking Universitário Folha (RUF), do Guia do Estudante (GUIA) e do Censo da Educação Superior - micro dados e sinopses estatísticas. Os dados obtidos do RUF e do GUIA abrangem o período de 2014-2018, os referentes ao MEC, de 2013-2017.

\section{Universidades Católicas frente aos indicadores de qualidade mensurados pelos Rankintacs.}

De acordo com os dados do Portal do e-MEC, atualmente, o Brasil conta com 72 universidades privadas sem fins lucrativos, das quais 19 universidades são confessionais católicas, ou seja, quase $1 / 3$ deste conjunto. Diferentemente das universidades privadas "com fins lucrativos", o 
segmento privado confessional não deve ser confundido com o novo ensino privado, pois este apresenta "caráter marcadamente empresarial, enquanto aquele não visa a acumulação de capital” (MARTINS, 1987, p. 55).

O Quadro 1 apresenta um panorama de distribuição das Católicas no território Brasileiro por Unidade Federativa, bem como, ano e Decreto de Reconhecimento pelo Governo Federal. Desse conjunto, $14(73,7 \%)$ estão situadas na região sul e sudeste do país, enquanto três $(15,8 \%)$ no Centro-oeste e duas (10,5\%) na regiáo nordeste. A região Norte do país não conta com Universidades Católicas. A maioria destes estabelecimentos estão concentrados em São Paulo e Rio Grande do Sul com cinco universidades cada $(52,6 \%)$ do total. Cabe destacar que o estado gaúcho chegou a esse número recentemente, com a autorizaçáo de mudança de organização acadêmica de dois Centros Universitários para universidade, a Universidade La Salle (UNILASALLE) em 2017 e, a Universidade Franciscana (UNF), em 2018. No entanto, estas duas últimas, por terem recém estabelecido nessa condição, não reuniram elementos suficientes para compor está análise, dado ao aspecto histórico longitudinal deste estudo.

\begin{tabular}{|c|l|c|c|c|c|}
\hline PORTE & \multicolumn{1}{|c|}{ UNIVERSIDADE } & Sigla & UF & Ano & Decreto \\
\hline Médio & Pontifícia Universidade Católica do Rio de Janeiro & PUC-RIO & RJ & 1946 & $\mathrm{~N}^{\circ} 868115 / 01 / 1946$ \\
\hline Médio & Pontifícia Universidade Católica de São Paulo & PUCSP & SP & 1946 & $\mathrm{~N}^{\circ} 963205 / 09 / 1946$ \\
\hline Grande & $\begin{array}{l}\text { Pontifícia Universidade Católica do Rio Grande do } \\
\text { Sul }\end{array}$ & PUCRS & RS & 1948 & $\mathrm{~N}^{\circ} 2579409 / 11 / 1948$ \\
\hline Médio & Universidade Católica de Pernambuco & UNICAP & PE & 1952 & $\mathrm{~N}^{\circ} 3041708 / 02 / 1952$ \\
\hline Médio & Pontifícia Universidade Católica de Campinas & PUC-CAMPINAS & SP & 1955 & $\mathrm{~N}^{\circ} 3832728 / 12 / 1955$ \\
\hline Grande & Pontifícia Universidade Católica de Minas Gerais & PUC MINAS & MG & 1958 & $\mathrm{~N}^{\circ} 4504612 / 12 / 1958$ \\
\hline Grande & Pontifícia Universidade Católica de Goiás & PUC GOIÁS & GO & 1959 & $\mathrm{~N}^{\circ} 4704117 / 10 / 1959$ \\
\hline Grande & Pontifícia Universidade Católica do Paraná & PUCPR & PR & 1960 & $\mathrm{~N}^{\circ} 4823214 / 06 / 1960$ \\
\hline Pequeno & Universidade Católica de Pelotas & UCPEL & $\mathrm{RS}$ & 1960 & $\mathrm{~N}^{\circ} 4908812 / 11 / 1960$ \\
\hline Médio & Universidade Católica do Salvador & UCSAL & $\mathrm{BA}$ & 1961 & $\mathrm{~N}^{\circ} 5819 / 10 / 1961$ \\
\hline Pequeno & Universidade Católica de Petrópolis & UCP & $\mathrm{RJ}$ & 1962 & $\mathrm{~N}^{\circ} 38321 / 12 / 1961$ \\
\hline Grande & Universidade do Vale do Rio dos Sinos & UNISINOS & $\mathrm{RS}$ & 1969 & $\mathrm{~N}^{\circ} 72201 / 08 / 1969$ \\
\hline Médio & Universidade São Francisco & USF & $\mathrm{SP}$ & 1985 & $\mathrm{~N}^{\circ} 82130 / 10 / 1985$ \\
\hline Pequeno & Universidade Católica de Santos & UNSANTOS & $\mathrm{SP}$ & 1986 & $\mathrm{~N}^{\circ} 10607 / 02 / 1986$ \\
\hline Pequeno & Universidade do Sagrado Coração & $\mathrm{SP}$ & 1986 & $\mathrm{~N}^{\circ} 29602 / 05 / 1986$ \\
\hline Médio & Universidade Católica Dom Bosco & UCDB & $\mathrm{MS}$ & 1993 & $\mathrm{~N}^{\circ} 154728 / 10 / 1993$ \\
\hline Médio & Universidade Católica de Brasília & UCB & DF & 1994 & $\mathrm{~N}^{\circ} 182730 / 12 / 1994$ \\
\hline Médio & Universidade La Salle & UNILASALLE & $\mathrm{RS}$ & 2017 & $\mathrm{~N}^{\circ} 59708 / 05 / 2017$ \\
\hline Médio & Universidade Franciscana & $\mathrm{RS}$ & 2018 & $\mathrm{~N}^{\circ} 25923 / 03 / 2018$ \\
\hline
\end{tabular}

\section{Quadro 1: Classificaçáo das Universidade Católicas Brasileiras por} porte, ano de reconhecimento e Ato Regulatório de Credenciamento

Fonte: Elaborado pelos autores com base no e-MEC (BRASIL, 2018) e RUF (2018). 
O desempenho das universidades católicas será abordado a partir dos Rankings nacionais, elaborados pelo MEC e pelo Instituto Nacional de Estudos e Pesquisas Educacionais Anísio Teixeira (INEP), e os promovidos pelo setor privado, RUF e GUIA.

Esta análise, não visa discutir a legitimidade destes Rankintacs, mas sim, pautar-se em verificar o posicionamento das Católicas acompanhando seus respectivos desempenhos. Pois, apesar das críticas existentes, os rankings passaram a exercer influência, cada vez maior sobre as universidades, muitas das quais passaram a se preocupar com seus resultados, exaltando seus desempenhos em seus portais institucionais. Em 2014, a European University Association (EUA) informou que 60\% dos representantes das universidades europeias indicaram que os rankings desempenhavam um papel importante na sua estratégia institucional, enquanto $75 \%$ usavam classificaçôes em materiais de marketing e publicidade. Com um crescimento táo rápido no uso dos rankings, juntamente com avanços tecnológicos e acessibilidade à informaçóes online, as universidades continuarão a usar dados de classificaçôes para estabelecer comparaçôes com outras IES, bem como para manter e melhorar sua reputação e influência globais e regionais (WEST; MATTIS; PHILIPPOU, 2019).

Santos e Noronha (2016, p. 1) destacam que os rankings "têm alcançado importância crescente, influenciando políticas, processos avaliativos, decisões de investimento e reestruturação institucional". Sob esta perspectiva Ganga-Contreras et al (2018, p. 334) afirmam, também, que:

Distintos instrumentos han surgido y proliferado buscando mayor transparencia en los diferentes sistemas de educación superior en el mundo, siendo los rankings académicos los que han alcanzado una mayor popularidad y visibilidad. Cada uno define sus propios indicadores, y hace comparaciones a partir de un ideal de universidad que debe ser tomado como modelo para todas. Esta restricción (junto a otras) empuja a la creación de listados regionales y locales, enfocados en comprender y explicar de mejor forma la realidad de una zona o pais determinado.

No contexto atual, em que a racionalidade na gestão universitária tende a falar mais alto, as Católicas, dentro de suas características confes- 
sionais, guardiãs da fé cristã, presentes no mundo inteiro, encontram-se na eminência de rever seus padróes e conceitos, pois os tempos de outrora "ao longo das décadas de 70 e 80 , quando da hegemonia das universidades públicas e das universidades confessionais, dificilmente se poderia falar da existência de um mercado de ensino universitário" (CALDERÓN, 2000, p. 63).

Leva (2016) aponta que as Católicas são conhecidas e reconhecidas pelo volume de pesquisas apresentadas, onde, nesse espaço de desenvolvimento do saber, todas tendem para um objetivo, que é o reconhecimento. Essa busca vem ao encontro do conceito de "prestígio e reputação", apontado por Ordorika (2010) que também, se faz presente nessas IES que:

Esforçam para estar no ranking das melhores agremiaçóes acadêmicas e ser reconhecidas nacional e internacionalmente. A universidade católica busca sua excelência no conhecimento, mas prima pela identidade à qual é chamada. As universidades, sobretudo as Católicas, devem ser sal e luz no ambiente acadêmico (LEVA, 2016, p. 11).

\section{Universidades Católicas no Ranking Universitário Folha (RUF)}

As Católicas, em relação aos rankings acadêmicos, sempre ocuparam lugar de destaque entre as melhores do país, muitas delas a frente de grandes universidades públicas, no entanto, neste universo há uma diversidade muito grande, pois renomadas IES, não exibem resultados tão favoráveis. A Tabela 1 apresenta o posicionamento destas universidades no RUF nos últimos cinco anos.

O que destaca as Católicas, além de sua reconhecida tradição no âmbito de sua regionalidade é o bom posicionamento no cenário nacional. De acordo com o RUF, 12 Católicas, de um conjunto de 17, estão entre as 100 melhores do país (RUF, 2018). No entanto, quando analisamos essas universidades, segmentadas por porte - nos indicadores de pesquisa científica; qualidade do ensino; internacionalização; mercado de trabalho 
e; inovação - mensurados pelo RUF (2018), constata-se a presença em três grupos (pequeno, médio e grande porte), conforme Quadro 1 e Tabela 1.

Tabela 1: Posicionamento no RUF das Universidades Católicas brasileiras nos últimos cinco anos, considerando o número de Universidades por ano e seu posicionamento por porte, entre as Universidades privadas, de acordo com o número de alunos

\begin{tabular}{|c|c|c|c|c|c|c|c|c|}
\hline \multirow[b]{2}{*}{ Porte } & \multirow[b]{2}{*}{ Universidades } & \multirow{2}{*}{$\begin{array}{c}\text { No } \\
\text { alunos }\end{array}$} & \multicolumn{6}{|c|}{ Posicionamento } \\
\hline & & & 2014 & 2015 & 2016 & 2017 & 2018 & $\begin{array}{c}\text { Por Porte } \\
2018\end{array}$ \\
\hline \multirow{5}{*}{ Grande } & PUCRS & 20.410 & $18^{\circ}$ & $20^{\circ}$ & $22^{\circ}$ & $18^{\circ}$ & $18^{\circ}$ & $1^{\circ}$ \\
\hline & PUCPR & 23.129 & $32^{\circ}$ & $31^{\circ}$ & $32^{\circ}$ & $32^{\circ}$ & $31^{\circ}$ & $2^{\circ}$ \\
\hline & UNISINOS & 25.017 & $43^{\circ}$ & $45^{\circ}$ & $39^{\circ}$ & $35^{\circ}$ & $36^{\circ}$ & $4^{-0}$ \\
\hline & PUC MINAS & 46.839 & $42^{\circ}$ & $47^{\circ}$ & $51^{\circ}$ & $61^{\circ}$ & $56^{\circ}$ & $6^{\circ}$ \\
\hline & PUC GOIÁS & 23.812 & $94^{\circ}$ & $114^{\circ}$ & $106^{\circ}$ & $104^{\circ}$ & $106^{\circ}$ & $20^{\circ}$ \\
\hline \multicolumn{8}{|c|}{ Número de Universidades privadas de grande porte 2018} & 37 \\
\hline \multirow{8}{*}{ Médio } & PUC-RIO & 15.304 & $20^{\circ}$ & $19^{\circ}$ & $21^{\circ}$ & $20^{\circ}$ & $19^{\circ}$ & $1^{\circ}$ \\
\hline & UCB & 10.669 & $48^{\circ}$ & $55^{\circ}$ & $50^{\circ}$ & $47^{\circ}$ & $45^{\circ}$ & $2^{-}$ \\
\hline & PUCSP & 15.885 & $54^{\circ}$ & $53^{\circ}$ & $55^{\circ}$ & $51^{\circ}$ & $54^{\circ}$ & $3^{-}$ \\
\hline & PUC-CAMPINAS & 15.832 & $80^{\circ}$ & $67^{\circ}$ & $77^{\circ}$ & $60^{\circ}$ & $65^{\circ}$ & $4^{0}$ \\
\hline & UNICAP & 9.795 & $103^{\circ}$ & $99^{\circ}$ & $114^{\circ}$ & $96^{\circ}$ & $91^{\circ}$ & $11^{\circ}$ \\
\hline & USF & 12.103 & $51^{\circ}$ & $70^{\circ}$ & $70^{\circ}$ & $82^{\circ}$ & $93^{\circ}$ & $12^{\circ}$ \\
\hline & UCDB & 9.932 & $149^{\circ}$ & $146^{\circ}$ & $146^{\circ}$ & $109^{\circ}$ & $97^{\circ}$ & $14^{\circ}$ \\
\hline & UCSAL & 8.909 & $140^{\circ}$ & $164^{\circ}$ & $159^{\circ}$ & $162^{\circ}$ & $166^{\circ}$ & $29^{\circ}$ \\
\hline \multicolumn{8}{|c|}{ Número de Universidades privadas de médio porte 2018} & 31 \\
\hline \multirow{4}{*}{ Pequeno } & UCPEL & 3.829 & $117^{\circ}$ & $86^{\circ}$ & $87^{\circ}$ & $70^{\circ}$ & $76^{\circ}$ & $2^{-}$ \\
\hline & USC & 5.318 & $119^{\circ}$ & $122^{\circ}$ & 960 & $108^{\circ}$ & $111^{\circ}$ & $4^{-}$ \\
\hline & UNISANTOS & 5.123 & $102^{\circ}$ & $169^{\circ}$ & $153^{\circ}$ & $146^{\circ}$ & $148^{\circ}$ & $7^{0}$ \\
\hline & UCP & 5.537 & $162^{\circ}$ & $174^{\circ}$ & $183^{\circ}$ & $181^{\circ}$ & $182^{\circ}$ & $16^{\circ}$ \\
\hline \multicolumn{8}{|c|}{ Número de Universidades privadas de pequeno porte 2018} & 21 \\
\hline & úmero total & 257.443 & 196 & 192 & 195 & 195 & 196 & \\
\hline
\end{tabular}

Fonte: RUF 2014, 2015, 2016, 2017 e 2018; Censo da Educação Superior 2017 (BRASIL, 2017a). 
Qualidade da educação superior no Brasil: desempenho das universidades católicas à luz dos rankings acadêmicos, índices e tabelas classificatórias estatais e do setor privado

Para analisarmos mais atentamente a Tabela 1, lançamos mão da estatística descritiva, por meio de separatrizes, que segundo Feijoo (2010) são valores da distribuição que as dividem em partes iguais, e tem como objetivo proporcionar uma melhor ideia da dispersão do conjunto, um exemplo é a divisão do conjunto em quartis. Quando aplicamos este critério de separatrizes/quartil nas Católicas, de acordo com seu porte, a configuração fica conforme expresso na figura 1.

De acordo com o RUF, três universidades com desempenho excelente, de grande porte PUCRS e duas de médio porte, PUC-RIO e UCB, nenhuma de pequeno porte alcançou este status. Com desempenho fraco, três universidades enquadram-se neste quesito, de grande porte, PUC GOIÁS, de médio porte, UCSAL e de pequeno porte, UCP. Com bom desempenho destacaram-se duas Católicas de grande porte, PUCPR e UNISINOS, quatro de médio porte: PUCSP, PUC-CAMPINAS, UNICAP e USF e uma de pequeno porte (UCPEL). Desempenho regular, temos PUC MINAS, de médio porte, UCDB e duas de porte pequeno, UNISANTOS e USC.

\begin{tabular}{|c|c|c|c|}
\hline $1^{\circ}$ Quartil & $\begin{array}{l}\text { Desempenho Universidades } \\
\qquad 2^{\circ} \text { Quartil }\end{array}$ & $\begin{array}{l}\text { Católicas de Grande Porte } \\
\qquad 3^{\circ} \text { Quartil }\end{array}$ & $4^{\circ}$ Quartil \\
\hline Desempenho Excelente & Desempenho Bom & Desempenho Regular & Desempenho Fraco \\
\hline PUCRS & $\begin{array}{l}\text { PUCPR } \\
\text { UNISINOS }\end{array}$ & PUC MINAS & PUC GOIÁS \\
\hline $1^{\circ}$ Quartil & $\begin{array}{l}\text { Desempenho Universidades } \\
\qquad 2^{\circ} \text { Quartil }\end{array}$ & $\begin{array}{l}\text { Católicas de Médio Porte } \\
\qquad 3^{\circ} \text { Quartil }\end{array}$ & $4^{\circ}$ Quartil \\
\hline Desempenho Excelente & Desempenho Bom & Desempenho Regular & Desempenho Fraco \\
\hline $\begin{array}{l}\text { PUC-RIO } \\
\text { UCB }\end{array}$ & $\begin{array}{c}\text { PUCSP } \\
\text { PUC-CAMPINAS } \\
\text { UNICAP } \\
\text { USF } \\
\end{array}$ & UCDB & UCSAL \\
\hline $1^{\circ}$ Quartil & $\begin{array}{c}\text { Desempenho Universidades } \\
2^{\circ} \text { Quartil }\end{array}$ & $\begin{array}{l}\text { Católicas de Pequeno Porte } \\
\qquad 3^{\circ} \text { Quartil }\end{array}$ & $4^{\circ}$ Quartil \\
\hline Desempenho Excelente & Desempenho Bom & Desempenho Regular & Desempenho Fraco \\
\hline $\begin{array}{c}\text { Nenhuma Úniversidade } \\
\text { Católica }\end{array}$ & UCPEL & $\begin{array}{l}\text { UNISANTOS } \\
\text { USC }\end{array}$ & UCP \\
\hline
\end{tabular}

Figura 1: Desempenho das Universidades Católicas brasileiras no Ranking Universitário Folha (RUF)-

Fonte: Elaborado pelos autores com base no RUF (2018). 
Essas universidades são responsáveis pela formação de profissionais nas mais diversas áreas do conhecimento com qualidade reconhecida. Tal reconhecimento, salvo algumas exceçôes, se deve pelos desempenhos apontados na Tabela 1. Esse reconhecimento, também se revela em relação aos cursos de graduação oferecidos. Analisando os cursos de graduação com maior número de ingressantes no país, avaliados pelo RUF (2018), verifica-se que os mesmos são oferecidos, em sua grande maioria, pelas Católicas. Sua presença nas mais diversas áreas do conhecimento é de grande relevância no cenário educacional brasileiro, destacando as de grande porte, que oferecem mais de $80 \%$ dos cursos de graduação com maior número de ingressantes do país.

Cabe destacar, que dentro de suas características filantrópicas, essas IES têm trazido importantes contribuiçóes por meio do seu compromisso com os cursos de licenciaturas, cursos que em sua maioria são deficitários, dado a baixa procura, conforme números de matrículas apontados pelo último censo da educação superior (BRASIL, 2017a).

A avaliação anual dos 40 cursos com maior número de ingressantes no país pelo RUF (2018) tem como referência dados nacionais e internacionais ${ }^{3}$, considerando dois aspectos, ensino e mercado. Tendo o "mercado" com 36\% do total da nota, para compor este indicador foi considerado a opinião de 5.444 profissionais de Recursos Humanos consultados pela Datafolha em 2016, 2017 e 2018 sobre preferências de contratação.

Já o indicador "ensino" possui $64 \%$ do total da nota, levando em conta quatro componentes: avaliadores do MEC (40\%), pesquisa feita pelo Datafolha em 2016, 2017 e 2018 com amostra de 2.381 entrevistas com professores distribuídos pelo país para analisar a qualidade de cursos superiores; professores com doutorado e mestrado (8\%); professores em dedicação integral e parcial (8\%) e; nota no Exame Nacional de Desempenho de Estudantes (ENADE) (8\%), considerando a média da universidade no ENADE de 2014, 2015 e 2016.

Frente aos contínuos questionamentos em relação às classificaçôes inauguradas pelos rankings e listas classificatórias de não levarem em conta algumas particularidades institucionais, o RUF, em 2018, trouxe mais um elemento visando contribuir para o processo de comparação, que é a possibilidade de distinguir as universidades por porte (grande, médio e 
pequeno), esse novo fator admitiu comparar o comparável. A partir dessa distinção, além de permitir ter o panorama das Católicas no cenário da educação superior no Brasil, também estabeleceu uma nova categoria para análise. Dessa forma, poder analisar as universidades de acordo com suas particularidades, categorizando-as (pública, privada, porte, regiāo), tornase o processo de comparaçáo mais justo.

\section{Universidades Católicas no Guia do Estudante}

$\mathrm{Na}$ mesma direção que o RUF, o ranking GUIA divulgado, de 1984 a 2018, sempre apresentou, no conjunto de suas publicaçôes, além de apostilas com conteúdo para vestibulares e resumos sobre atualidades, publicava avaliaçóes dos cursos superiores oferecidos no Brasil e, anualmente, de 2006 a 2018, premiava 20 universidades públicas e 20 universidades privadas com o "Prêmio melhores Universidades". De acordo com Lourenço $(2014$, p. 8) a avaliação de cursos promovida pelo GUIA náo passa despercebida e "os bons resultados surtem efeitos em termos de gestão acadêmica, de divulgação institucional e de suporte mercadológico, tanto nos segmentos de educação superior público e particular", fato que revela a importância de se analisar a influência desse ranking presente no cotidiano das universidades.

O GUIA mensurou, em 2018, a "qualidade" de mais de 17 mil cursos de graduação do país. A avaliação tratava-se de "uma pesquisa de opinião feita, basicamente, com professores e coordenadores de curso. Eles emitem conceitos que permitem classificar os cursos em bons (três estrelas), muito bons (quatro estrelas) e excelentes (cinco estrelas)". De acordo com o GUIA (2018, p. 36), a partir de 2016 cada curso passou a ser avaliado sob três aspectos: projeto didático-pedagógico, corpo docente e, infraestrutura.

Cada curso segue alguns critérios 5 para obter o conceito final, o qual define a quantidade de estrelas, de acordo com esses critérios, os cursos podem ganhar ou perder estrelas de um ano para outro. (Tabela 2)

Considerando que o GUIA atribui o "Prêmio Melhores Universidades" àquelas IES que se destacaram entre seus pares, neste grupo de excelência, também, podemos analisar, pontualmente, o desempe- 
Tabela 2: Posicionamento das Universidades Católicas brasileiras no Prêmio Melhores Universidades - Guia do Estudante, nos últimos cinco anos

\begin{tabular}{|c|c|c|c|c|c|c|}
\hline \multicolumn{1}{|c|}{ Universidades } & Porte & 2014 & 2015 & 2016 & 2017 & 2018 \\
\hline PUCRS & Grande & $2^{\circ}$ & $2^{\circ}$ & $2^{\circ}$ & $1^{\circ}$ & $1^{\circ}$ \\
\hline PUC-RIO & Médio & $3^{\circ}$ & $1^{\circ}$ & $1^{\circ}$ & $2^{\circ}$ & $2^{\circ}$ \\
\hline PUC MINAS & Grande & $1^{\circ}$ & $3^{\circ}$ & $6 \circ$ & $5 \circ$ & $4^{\circ}$ \\
\hline UNISINOS & Grande & $6^{\circ}$ & $4^{\circ}$ & $4^{\circ}$ & $7 \circ$ & $5^{\circ}$ \\
\hline PUCPR & Grande & $5^{\circ}$ & $5^{\circ}$ & $7^{\circ}$ & $6^{\circ}$ & $6^{\circ}$ \\
\hline PUCSP & Médio & $7^{\circ}$ & $6^{\circ}$ & $3^{\circ}$ & $9^{\circ}$ & $7^{\circ}$ \\
\hline PUC-CAMPINAS & Médio & $8^{\circ}$ & $9^{\circ}$ & $12^{\circ}$ & $11^{\circ}$ & $10^{\circ}$ \\
\hline UCB & Médio & $16^{\circ}$ & $12^{\circ}$ & $15^{\circ}$ & $14^{\circ}$ & $12^{\circ}$ \\
\hline PUC GOIÁS & Grande & $14^{\circ}$ & $18^{\circ}$ & $18^{\circ}$ & $16^{\circ}$ & $20^{\circ}$ \\
\hline
\end{tabular}

Fonte: Guia do Estudante 2014, 2015, 2016, 2017 e 2018.

nho das Católicas, usando o critério estatístico descritivo por meio de separatrizes (FEIJOO, 2010), ou seja, dividimos este grupo de excelência em quartis, denominados, excelente, muito bom, bom e suficiente (Figura 2).

\begin{tabular}{|ccccc|}
\hline \multicolumn{4}{c|}{ NIVEIS DE EXCELÊNCIA } \\
EXCELENTE & MUITO BOM & BOM & SUFICIENTE & INSUFICIENTE \\
PUCRS & PUCPR & UCB & PUC GOIÁS & UNICAP \\
PUC-RIO & PUCSP & & & USF \\
PUC MINAS & PUC-CAMPINAS & & & UCDB \\
UNISINOS & & & UCSAL \\
& & & UCPEL \\
& & & USC \\
& & & UNISANTOS \\
& & & UCP \\
\hline
\end{tabular}

Figura 2: Classificação das Universidades Católicas brasileiras enquadradas entre as 20 melhores universidades do setor privado no Prêmio Melhores Universidades do Guia do Estudante - 2018

Fonte: Elaborado pelos autores com base no "Prêmio Melhores Universidades" do GUIA (2018). 
Dessa forma, PUCRS, PC-RIO, PUC MINAS e UNISINOS encontram-se num alto nível de excelência neste "Prêmio". PUCPR, PUCSP e PUC-CAMPINAS, num nível muito bom. UCB em bom nível e, PUC GOIÁS num nível suficiente de excelência.

Nos últimos cinco anos, entre as 20 universidades privadas que fazem parte do "Prêmio", nove Católicas (45\%) têm se destacado, oscilando algumas posiçóes, porém sempre presentes. $\mathrm{O}$ prêmio é alcançado, graças ao desempenho de seus cursos na avaliação do GUIA. Nesse cenário todas as Católicas de grande porte estão presentes, $50 \%$ das Católicas de médio porte também compóe o quadro (PUC-RIO, PUCSP, PUC-CAMPINAS e UCB). IES de porte médio como UNICAP, USF, UCDB e UCSAL, bem como todas as Católicas de pequeno porte, UCPEL, USC, UNISANTOS e UCP, náo alcançaram desempenho suficiente para compor o grupo das 20 melhores.

Cabe destacar que no "Prêmio Melhores Universidades" edição 2018, entre as Católicas, temos duas universidades com nível excelente desempenho que se destacam das demais, PUCRS que alcançou a expressiva marca de 21 cursos com cinco estrelas, sendo considerada a melhor universidade privada do país. A segunda posição ficou com outra católica, a PUC-RIO, contando com 20 cursos cinco estrelas. O desempenho expressivo destas duas universidades é verificado pela troca de liderança nos últimos cinco anos, a PUCRS figurou na primeira colocação nos últimos dois anos, porém essa posição foi ocupada por dois anos consecutivos, 2015 e 2016 pela PUC-RIO, enquanto, a PUC-MINAS, em 2014, ocupava essa posição.

O GUIA, também premia as melhores universidades por área do conhecimento $^{6}$, a Tabela 3 identifica as Católicas que se destacaram nas oito áreas avaliadas pelo ranking nos últimos cinco anos, evidenciando sua importância no cenário da educação superior no Brasil.

No segmento privado, as Católicas, são reconhecidas entre as melhores por área do conhecimento que, de acordo com o GUIA (2018), nos casos de empate, as instituiçóes estão listadas por ordem alfabética de nome, em todas as oito áreas avaliadas pelo GUIA: 1) Administração, negócios e serviços; 2) Ciências biológicas e da terra; 3) Saúde e bem-estar; 4) Ciências sociais e humanas; 5) Comunicação e informação; 6) Artes e design; 7) Ciências exatas e informática; 8) Engenharia e produção. 
$\mathrm{Na}$ área de Administração, Negócios e Serviços, a PUCRS, esteve presente por três anos consecutivos entre as melhores, PUCPR (duas vezes), PUCSP e UCB (uma vez), também ocuparam lugar de destaque nesse período nessa área. Nas Ciências Biológicas e da Terra, a UNISINOS possui excelente desempenho, pois esteve presente, quatro vezes, nos últimos cinco anos, a UCDB, apesar de não figurar entre as 20 do "Prêmio Melhores Universidades" (Tabela 2), foi destaque nessa área, por duas vezes, juntamente com a PUCPR, também figurou nessa área, a PUC MINAS (uma vez). Na área da Saúde e Bem-Estar, a PUCRS ocupou a primeira posição por quatro anos consecutivos, nessa área, destacam-se também, PUCPR (quatro vezes), PUC-Campinas (duas vezes) e PUC MINAS (Uma vez). (Tabela 3)

Nas áreas das Ciências Humanas e Sociais, Ciências Exatas e Informática e Engenharia de Produção, as Católicas sobressaem em relação às demais universidades privadas. Nessas três áreas, há presença maciça e quase que exclusiva dessas IES figurando as três primeiras colocaçóes nos últimos cinco anos. Exceção, apenas para o Centro Universitário FEI (três vezes) e Mackenzie, também confessional, porém de outra denominação religiosa (uma vez). Em Comunicação e Informação, a UNISINOS (três vezes) é a católica com melhor desempenho, seguida por PUCSP e PUCRS (duas vezes). Apesar de não ter a mesma performance em relação às demais áreas, as Católicas, na área de Artes e Design, ainda, sobressaem com a PUC-RIO (três vezes) e a PUCPR (uma vez).

Cabe ressaltar, que apesar de estar presente no seleto grupo das IES privadas no "Prêmio Melhores Universidades", a PUC GOIÁS sempre ocupou as últimas posiçóes no Prêmio, destoando do conjunto, assim como, também, não se destacaram, em nenhuma área do conhecimento, as Católicas USF, UNICAP, UCSAL, UNISANTOS, UCPEL, USC e UCP. Como se pode perceber, a qualidade entre as Católicas, medida pelos indicadores do GUIA, não é homogênea. Cenário ocupado por outras IES e, nem todas são universidades, como o caso, das Faculdades IBMEC-RJ, Centro Universitário SENAC-SP e Centro Universitário Belas Artes de São Paulo.

Em relação aos destaques regionais, também avaliados pelo GUIA, na qual são considerados, apenas os três primeiros colocados, verifica-se que as Católicas não estão inseridas em todas as regióes do país, por exemplo, a região Norte, não é assistida com nenhuma destas IES, enquanto 


\section{Tabela 3: Posicionamento das três primeiras Universidades Católicas brasileiras classificadas pelo Guia do Estudante, por área de conhecimento nos últimos cinco anos}

\begin{tabular}{|c|c|c|c|c|c|c|}
\hline \multicolumn{2}{|c|}{$\begin{array}{c}\text { Área de } \\
\text { Conhecimento* }\end{array}$} & 2014 & 2015 & 2016 & 2017 & 2018 \\
\hline \multirow{6}{*}{$\begin{array}{c}\text { Administração, } \\
\text { Negócios e } \\
\text { Serviços. }\end{array}$} & \multirow{3}{*}{$1^{\mathrm{a}}$} & \multirow{3}{*}{$\begin{array}{l}\text { Anhembi } \\
\text { Morumbi }\end{array}$} & \multirow{3}{*}{$\begin{array}{l}\text { Anhembi } \\
\text { Morumbi }\end{array}$} & \multirow{3}{*}{ Ibmec-RJ } & \multirow{3}{*}{ Ibmec-RJ } & Ibmec-RJ/ \\
\hline & & & & & & Mackenzie/ \\
\hline & & & & & & $\mathrm{UCB}$ \\
\hline & $2^{a}$ & PUCPR & PUCRS & $\begin{array}{l}\text { Anhembi } \\
\text { Morumbi }\end{array}$ & Mackenzie & - \\
\hline & \multirow{2}{*}{$3^{\mathrm{a}}$} & \multirow{2}{*}{ Ibmec-RJ } & \multirow{2}{*}{ PUCSP } & \multirow{2}{*}{ PUCRS } & PUCPR/ & \multirow{2}{*}{ - } \\
\hline & & & & & PUCRS & \\
\hline \multirow{4}{*}{$\begin{array}{c}\text { Ciências } \\
\text { Biológicas e da } \\
\text { Terra }\end{array}$} & \multirow{2}{*}{$1^{\mathrm{a}}$} & \multirow{2}{*}{ UPF } & \multirow{2}{*}{ UPF } & \multirow{2}{*}{ Unoeste } & $\mathrm{UCDB} /$ & \multirow{2}{*}{ Unoeste } \\
\hline & & & & & Unoeste & \\
\hline & $2^{a}$ & UNISINOS & UCDB & UPF & - & UNISINOS \\
\hline & $3^{\mathrm{a}}$ & PUC MINAS & UNISINOS & PUCPR & UNISINOS & PUCPR \\
\hline \multirow{3}{*}{$\begin{array}{l}\text { Saúde e } \\
\text { Bem-estar }\end{array}$} & $1^{\mathrm{a}}$ & PUC MINAS & PUCRS & PUCRS & PUCRS & PUCRS \\
\hline & $2^{a}$ & Unifor-CE & $\begin{array}{c}\text { PUC- } \\
\text { CAMPINAS }\end{array}$ & PUCPR & PUCPR & Unifor-CE \\
\hline & $3^{\mathrm{a}}$ & PUCPR & Unifor-CE & $\begin{array}{l}\text { Anhembi } \\
\text { Morumbi }\end{array}$ & $\begin{array}{c}\text { PUC- } \\
\text { CAMPINAS } \\
\end{array}$ & PUCPR \\
\hline \multirow{3}{*}{$\begin{array}{c}\text { Ciências Sociais } \\
\text { e Humanas }\end{array}$} & $1^{\mathrm{a}}$ & PUC-RIO & PUC-RIO & PUC-RIO & PUC-RS & PUC-RIO \\
\hline & $2^{a}$ & PUCSP & PUCSP & PUC-RS & PUC-RIO & PUCRS \\
\hline & $3^{\mathrm{a}}$ & PUC-RS & PUC MINAS & PUCSP & PUCSP & PUC MINAS \\
\hline \multirow{6}{*}{$\begin{array}{l}\text { Comunicação e } \\
\text { Informaçấo }\end{array}$} & \multirow{2}{*}{$1^{\mathrm{a}}$} & \multirow{2}{*}{ UNISINOS } & \multirow{2}{*}{ Metodista } & \multirow{2}{*}{ Metodista } & PUCSP & \multirow{2}{*}{ UNISINOS } \\
\hline & & & & & PUCRS & \\
\hline & \multirow{2}{*}{$2^{\mathrm{a}}$} & \multirow{2}{*}{ Metodista } & \multirow{2}{*}{ UNISINOS } & PUCSP & 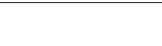 & Cósner I ́iber \\
\hline & & & & PUCRS & - & Casper Libero \\
\hline & $3 a$ & Anhembi & Anhembi & 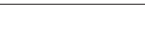 & Anhembi & PUCSP \\
\hline & $3^{a}$ & Morumbi & Morumbi & - & Morumbi & PUCRS \\
\hline & $1^{\mathrm{a}}$ & Belas Artes & $\begin{array}{l}\text { Anhembi } \\
\text { Morumbi }\end{array}$ & Senac-SP & PUC-RIO & Senac-SP \\
\hline Artes e Design & $2^{a}$ & Senac-SP & Belas Artes & Belas Artes & Senac-SP & Belas Artes \\
\hline & $3 a$ & $\mathrm{H}$ & & & Anhembi & PUCPR \\
\hline & $3^{a}$ & UniRitter & 5 & $P$ & & PUC-RIO \\
\hline & $1^{\mathrm{a}}$ & PUC-RIO & PUC-RIO & PUC-RIO & PUC-RIO & PUC-RIO \\
\hline $\begin{array}{l}\text { Ciências Exatas } \\
\text { e Informática }\end{array}$ & $2^{a}$ & PUCRS & PUCRS & PUCRS & PUCRS & PUCRS \\
\hline & $3^{a}$ & PUCPR & PUCPR & Mackenzie & PUCPR & PUCPR \\
\hline & $1^{\mathrm{a}}$ & PUC-RIO & PUC-RIO & PUC-RIO & PUC-RIO & PUC-RIO \\
\hline $\begin{array}{c}\text { Engenharia e } \\
\text { Producão }\end{array}$ & $2^{a}$ & PUCRS & FEI & PUCRS & FEI & FEI \\
\hline & $3^{a}$ & PUCPR & PUCPR & FEI & PUCRS & PUCRS \\
\hline
\end{tabular}

*De acordo com o Guia do Estudante (2018), nos casos de empate, as instituiçôes estão listadas por ordem alfabética de nome.

Fonte: Guia do Estudante 2014, 2015, 2016, 2017 e 2018. 


\begin{tabular}{|l|c|c|c|c|c|}
\hline REGIÃ0 & $\mathbf{2 0 1 4}$ & $\mathbf{2 0 1 5}$ & $\mathbf{2 0 1 6}$ & $\mathbf{2 0 1 7}$ & $\mathbf{2 0 1 8}$ \\
\hline \multirow{4}{*}{ Norte } & UNAMA & UNAMA & UNAMA & CEULP/ULBRA & FAMAZ \\
\cline { 2 - 6 } & CESUPA & CESUPA & FUCAPI-AM & FEAPA & CEULP/ULBRA \\
\cline { 2 - 6 } & Fac. São Lucas & FAMETRO & FEAPA & UNINORTE & FAMETRO \\
\hline \multirow{4}{*}{ Nordeste } & UNIFOR-CE & UNIFOR-CE & UNIFOR-CE & UNIFOR-CE & UNIFOR-CE \\
\cline { 2 - 6 } & UNICAP & FA7-CE & UNIT-SE & UNIT-SE & UNIT-SE \\
\cline { 2 - 6 } & UNIFACS & UNP & FA7-CE & UNICAP & UNICAP \\
\hline \multirow{3}{*}{$\begin{array}{l}\text { Oeste } \\
\text { Sudeste }\end{array}$} & PUC-GOIÁS & UCB-DF & UCB-DF & UCB-DF & UCB-DF \\
\cline { 2 - 6 } & UCB-DF & PUC-GOIÁS & PUC-GOIÁS & PUC GOIÁS & PUC GOIÁS \\
\cline { 2 - 6 } & UniCEUB & UCDB & UCDB & UCDB & UCDB \\
\cline { 2 - 6 } & PUC MINAS & PUC-RIO & PUC-RIO & PUC-RIO & PUC-RIO \\
\cline { 2 - 6 } & PUC-RIO & PUC MINAS & PUCSP & FGV & FGV \\
\cline { 2 - 6 } & PUCSP & PUCSP & MACKENZIE & MACKENZIE & PUC MINAS \\
\cline { 2 - 6 } & UCS & PUCRS & PUCRS & PUCRS & PUCRS \\
\cline { 2 - 6 } & PUCPR & UNISINOS & UNISINOS & PUCPR & UNISINOS \\
\hline
\end{tabular}

Quadro 2: Destaques das três primeiras IES privadas do país no período 2014-2018, por Regiáo, segundo o Guia do Estudante

Fonte: Guia do Estudante 2014, 2015, 2016, 2017 e 2018.

a região Nordeste, dos seis destaques regionais, de 2014 a 2018 destacou, apenas, a UNICAP.

$\mathrm{Na}$ regiáo Centro-Oeste, as três universidades destacadas são Católicas (PUC GOIÁS, UCB, UCDB), a UCDB, só não esteve entre os destaques em 2014. No Sul do país, ao longo do período analisado, os três destaques regionais são Católicas, PUCRS, PUCPR e UNISINOS.

A regiáo Sudeste, conta com o maior número de universidades do país, fator que influenciou nas oscilaçóes ao longo do período, de qualquer maneira, nos últimos cinco anos, das cinco universidades privadas, destaques regionais, três são Católicas, posiçôes ocupadas de forma alternadas, entre PUC MINAS, PUC-RIO e PUCSP. As universidades PUCCAMPINAS, USF, UCP, UNISANTOS e USC, não lograram destaque no período analisado.

\section{Desempenho das Universidades Católicas no Índice Geral de Cursos (IGC)}

O Índice Geral de Cursos (IGC) (BRASIL, 2015) é uma lista produzida pelo MEC desde 2007, resultante de dados do Censo da Educação 
Superior somados ao resultado do ENADE do ano anterior. Apesar de não se apresentar como um ranking, a mídia em geral faz uso de suas listas anuais, classificando, automaticamente as IES brasileiras (RIGHETTI, 2016). Náo obstante ser tratado como uma lista classificatória, o IGC, contribui para que estudantes do país possam conhecer o desempenho das IES e ser instrumento de decisão na hora de escolher seu futuro local de estudo.

Segundo o INEP (BRASIL, 2015), o IGC é um indicador de "qualidade" que avalia as IES. Seu cálculo é realizado anualmente e leva em conta os seguintes aspectos:

1. média do Conceito Preliminar de Curso (CPC) do último triênio, relativos aos cursos avaliados da instituição, ponderada pelo número de matrículas em cada um dos cursos computados;

2. média dos conceitos de avaliação dos programas de pós-graduação stricto sensu atribuídos pela Coordenaçáo de Aperfeiçoamento de Pessoal de Nível Superior (CAPES), fundação vinculada ao MEC, na última avaliação trienal disponível, convertida para escala compatível e ponderada pelo número de matrículas em cada um dos programas de pós-graduação correspondentes e;

3. distribuição dos estudantes entre os diferentes níveis de ensino, graduação ou pós-graduação stricto sensu, excluindo as informaçóes do item 2 para as instituiçóes que não oferecerem pós-graduação stricto sensu.

A Tabela 4 apresenta a classificação das Católicas, nos últimos cinco anos, em relação às demais universidades privadas do país, onde é possível classificá-las por seus respectivos IGC contínuos e Faixas, numa lista classificatória compreendida no âmbito dos Rankintacs.

Verifica-se, na Figura 3, que PUC-RIO, PUCSP, UNISINOS, PUCRS, PUCPR, UNISANTOS, PUC MINAS, USC e UCDB, obtiveram os melhores resultados entre as universidades privadas do país no IGC, dados do período de 2013-2017 (últimos cinco anos divulgados pelo MEC). Neste período, lideradas pela PUC-RIO, essas universidades vêm obtendo alto desempenho, com IGC na Faixa quatro, nessa lista classificatória. Cabe destacar que a UCDB, até 2016, estava com IGC Faixa três, no entanto, desde 2013 vem com IGC Contínuo crescente. Todas 
as Universidades constantes da Figura 3 tiveram crescimento no IGC Contínuo no ano de 2017 em relação ao ano anterior, com exceção da UNISINOS que teve uma leve queda no IGC Contínuo, mas mantendo se na Faixa 4, conforme se verifica na Figura 3 e na Tabela 4.

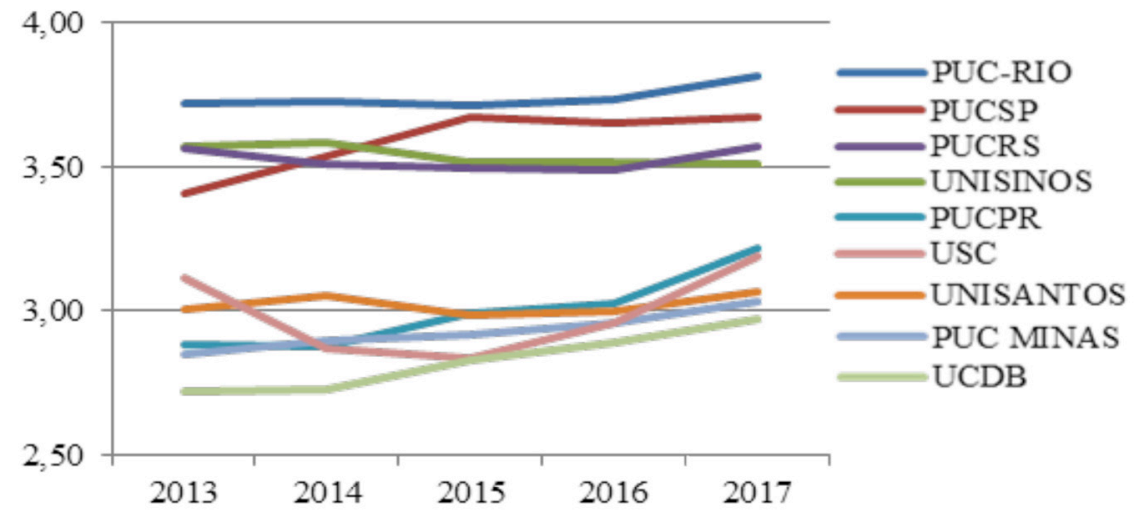

Figura 3: Universidades Católicas com desempenho na Faixa 4 do IGC Fonte: Adaptado de Relatório de consulta pública avançada - Portal e-MEC.

A Figura 4 sugere o cenário que se encontra $47 \%$ das Católicas brasileiras, IGC Contínuo entre 1,95 e 2,95, intervalo que compreende a nota três.

Para visualizar melhor o nível desempenho das Católicas no último IGC divulgado pelo MEC (BRASIL, 2017), usamos, também, o critério estatístico descritivo por meio de separatrizes em quartis (FEIJOO, 2010), tanto em relação às universidades brasileiras (públicas e privadas), quanto em relação aos seus pares (Católicas). Quando se estende para a listagem geral, contemplando todas as Universidades públicas e privadas do país, os resultados apontam que PUC-RIO, PUCSP, PUCRS e UNISINOS são as católicas com melhor desempenho neste ranking (Figura 5), com potencial maior, em relação às demais para alcançar a Faixa superior do IGC, pois vêm com desempenho crescente no IGC Contínuo, ficando cada vez mais próximas de mudar para a Faixa superior, se o histórico de crescimento se mantiver. 
Tabela 4: Posicionamento das Universidades Católicas brasileiras no IGC Contínuo entre as Universidades privadas, conforme Portal e-MEC

\begin{tabular}{|c|c|c|c|c|c|c|c|c|c|c|c|c|c|c|c|c|c|c|c|}
\hline \multirow{4}{*}{$\hat{\sigma}$} & $\mathrm{GC} \mathrm{F}$ & 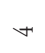 & $\nabla$ & 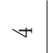 & 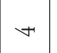 &  & 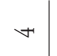 & $\nabla$ & 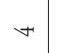 & $m$ & 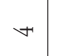 & $n$ & $n$ & $m$ & $m$ & $m$ & $m$ & $m$ & \\
\hline & & & 5 & & $\begin{array}{l}\tilde{n} \\
\tilde{m}\end{array}$ & & $m^{2}$ & & $\stackrel{\check{m}}{\vec{m}}$ & & i & & is & & & b) & 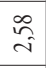 & & \\
\hline & NK & $\infty$ & 2 & 0 & নী & tु & $\infty$ & $\infty$ & 10 & $\approx$ & $\stackrel{9}{ }$ & $\approx$ & 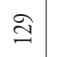 & ๔ & $\cong$ & 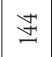 & 气ิ & \pm & \\
\hline & RNK & - & $\sim$ & $\nabla$ & $n$ & $=$ & $\approx$ & $\approx$ & $\simeq$ & w & $\hat{n}$ & $\approx$ & \&े & $\infty$ & 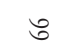 & 8 & $\nabla$ & $\infty$ & \\
\hline & $\mathrm{CF}$ & 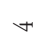 & tr & 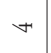 & $\nabla$ & 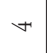 & $\nabla$ & + & 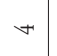 & s & $n$ & $n$ & $n$ & & & $n$ & $m$ & $n$ & \\
\hline & IGC & $\stackrel{\overbrace{}}{\sim}$ & 6 & & $\begin{array}{l}\mathscr{F} \\
\text { के }\end{array}$ & $\approx$ & $\begin{array}{c}8 \\
m \\
\end{array}$ & ॰ & $\stackrel{\text { ¿ }}{2}$ & & $\begin{array}{l}\stackrel{a}{\infty} \\
i\end{array}$ & & $\begin{array}{l}\stackrel{0}{i} \\
\text { in }\end{array}$ & & & $\pi$ & 우 & & \\
\hline & JK & & $\approx$ & & $\approx$ & $n$ & 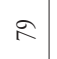 & $\infty$ & $\infty$ & $\infty$ & ๘゙ & 总 & $\Xi$ & $\approx$ & $\sim$ & $f$ & $\stackrel{n}{6}$ & 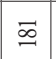 & \\
\hline & $\mathrm{R}$ & - & o & $m$ & + & $\stackrel{2}{2}$ & $=$ & 이 & $\vec{\lambda}$ & $\stackrel{\sim}{\sim}$ & ন & $\stackrel{m}{m}$ & 우 & & & 5 & $\approx$ & $\approx$ & \\
\hline & $\mathrm{F}$ & $\checkmark$ & $\checkmark$ & 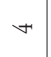 & $*$ & $\checkmark$ & $*$ & $m$ & $n$ & - & $n$ & r & $m$ & & & s & $m$ & $m$ & \\
\hline & I & 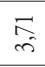 & 5 & & $\begin{array}{l}0 \\
\text { in }\end{array}$ & & 2 & & $\checkmark$ & & r & & v & & & & 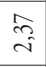 & & \\
\hline & RNK B & 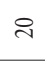 & $\vec{\sim}$ & & - & 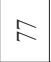 & $\infty$ & న & $\infty$ & 0 & $\sim$ &  & ๖ & & & $F$ & $\stackrel{0}{-}$ & 5 & \\
\hline & & & 0 & ণ & + & 0 & $=$ & $\overrightarrow{4}$ & $\approx$ & $\cong$ & 0 & & 0 & & & & 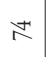 & 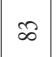 & \\
\hline & & & $\checkmark$ & & 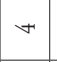 & $n$ & 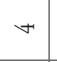 & $n$ & $n$ & 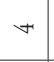 & $m$ & $m$ & $n$ & & & $m$ & $m$ & & \\
\hline & IC & & & & & & . & & 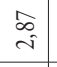 & & $\stackrel{i}{i}$ & & $\overrightarrow{\mathrm{i}}$ & & & & i & & \\
\hline & $\mathrm{R}$ & & 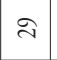 & & $\bar{m}$ & & 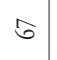 & & 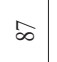 & b & 0 & $\circ$ & న & & & $\stackrel{7}{7}$ & $\odot$ & $\Xi$ & \\
\hline & & & & & $\psi$ & & $\approx$ & N & $\approx$ & & $\vec{F}$ & $\stackrel{\sim}{\sim}$ & 고 & & & 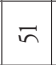 & $\stackrel{\infty}{\curvearrowright}$ & d. & \\
\hline \multirow{4}{*}{ 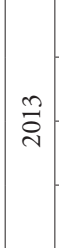 } & $\mathrm{CF}$ & & & & $\psi$ & & 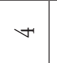 & $m$ & 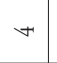 & & $m$ & $m$ & $m$ & s & & n & $m$ & & \\
\hline & C & & & & $\begin{array}{l}\tilde{n} \\
\tilde{m}\end{array}$ & & 每 & & 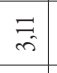 & & + & & & & & & $\overrightarrow{\vec{c}}$ & & \\
\hline & IK B & 5 & 7 & নે & $\pi$ & ㅇ & 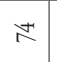 & 范 & $\sigma$ & $0^{\prime}$ & $\stackrel{\infty}{\circ}$ & & $=$ & 7 & & 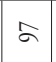 & $=$ & $\Xi$ & \\
\hline & 1 & 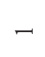 & $\checkmark$ & & $r$ & ? & $\infty$ & 1 & 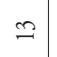 & 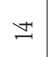 & $n$ & $\approx$ & $\stackrel{n}{m}$ & : & n & $\hat{2}$ & $\pi$ & $\infty$ & \\
\hline & $\overrightarrow{\mathrm{Z}}$ & نُ & $\begin{array}{l}\hat{\bar{n}} \\
\underline{\underline{Z}} \\
\underline{2}\end{array}$ & $\begin{array}{l}0 \\
0 \\
z \\
5 \\
z\end{array}$ & 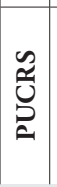 & 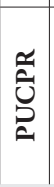 &  & 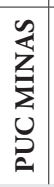 & $\begin{array}{l}u \\
\mathscr{D}\end{array}$ & $\begin{array}{l}\overrightarrow{1} \\
\hat{U} \\
\vec{D}\end{array}$ & 今ి & சి & 岕 & $\begin{array}{c}\dot{Z} \\
\text { Z } \\
\vdots\end{array}$ & 它莣 & $\vec{S}$ & 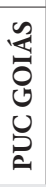 & 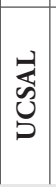 & \\
\hline
\end{tabular}

Legenda: RNKP= Ranking (classificação) entre as Universidades privadas brasileiras

$\mathrm{RNKB}=$ Ranking (classificaçáo) entre todas as Universidades brasileiras

IGCC = Índice Geral de Curso (IGC) Contínuo

IGCF= Índice Geral de Curso (IGC) Faixa

Fonte: Relatório de consulta pública avançada por IES - Portal e-MEC. (BRASIL, 2018). 


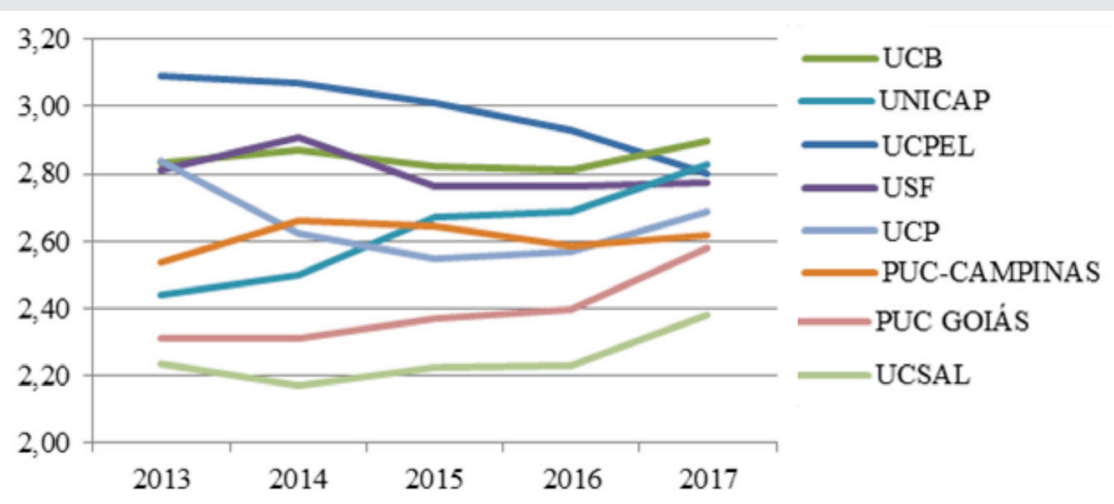

Figura 4: Católicas com desempenho na Faixa 3 do IGC

Fonte: Adaptado de Relatório de consulta pública avançada - Portal e-MEC (BRASIL, 2018).

\begin{tabular}{|c|c|c|c|}
\hline \multirow{2}{*}{$1^{\circ}$ Quartil } & \multicolumn{2}{|c|}{ Desempenho IGC } & \\
\hline Desempenho Excelente & $2^{\circ}$ Quartil & $3^{\circ}$ Quartil & $4^{\circ}$ Quartil \\
\hline PUCRS & Desempenho Bom & Desempenho Regular & Desempenho Fraco \\
PUC-RIO & PUCPR & UCDB & PUC-CAMPINAS \\
PUCPR & UNISANTOS & UNICAP & PUC GOIÁS \\
UNISINOS & UCPEL & UCSAL \\
& PUC MINAS & USF & \\
\hline
\end{tabular}

Figura 5: Desempenho das 17 Universidades Católicas no Cenário Nacional entre todas as Universidades brasileiras

Fonte: Elaborado pelos autores (IGC 2017).

Apesar de 53\% das Universidades Católicas apresentarem IGC 4, têm-se o grupo do $1^{\circ}$ quartil (Figura 5) com potencial para subir para a Faixa Superior (PUCRS, PUC-RIO, PUCPR e UNISINOS), as Universidades presentes no Quartil 2, estão na Faixa 4 do IGC, mas distantes ainda de chegar a Faixa 5 (PUCPR, USC, UNISANTOS, PUC MINAS e UCB), precisando se atentarem para a questão da qualidade, conforme critérios estabelecidos pelo MEC, para se manterem nesta Faixa. No terceiro quartil, têm-se (UCDB, ainda Faixa 4, UNICAP, UCPEL, USF e UCP), apesar de a UCDB ter alcançado a Faixa 4, graças ao seu desempenho crescente no IGC nos últimos anos, seu IGC contínuo está 
muito próximo da Faixa 3. UNICAP, UCPEL, USF e UCP, em relação à nota três, Faixa mínima para funcionamento, pode-se afirmar que estão numa zona de conforto, ou seja, distante da Faixa inferior.

PUC-CAMPINAS, PUC GOIÁS e UCSAL, ainda na Faixa 3, mas com desempenho fraco, em relação às outras Universidades brasileiras e entre as católicas (Figura 5). Neste cenário, a PUC GOIÁS, uma universidade de grande' porte, referência na regiáo centro-oeste do país, tem um dos piores desempenhos entre as católicas, ficando à frente, apenas da UCSAL (médio porte).

\begin{tabular}{|c|c|c|c|}
\hline & \multicolumn{2}{|c|}{ Desempenho IGC } & \\
\hline $1^{\circ}$ Quartil & $2^{\circ}$ Quartil & $3^{\circ}$ Quartil & $4^{\circ}$ Quartil \\
\hline Desempenho Excelente & Desempenho Bom & Desempenho Regular & Desempenho Fraco \\
\hline PUC-RIO & PUC MINAS & USF & PUC GOIÁS \\
PUCSP & UCB & UCSAL \\
PUCRS & UCDB & \\
UNISINOS & UNICAP & & \\
PUCPR & UCPC-CAMPINAS & \\
USC & & & \\
UNISANTOS & & & \\
\hline
\end{tabular}

Figura 6: Desempenho entre as 17 Universidades Católicas Brasileiras Fonte: Elaborado pelos autores (BRASIL, 2017).

Analisando o histórico de desempenho das Católicas, percebe-se que mesmo figurando o espaço das universidades de elevado desempenho (Faixa 4), a UNISINOS, apesar de manter certo equilíbrio nos últimos cinco anos, teve uma pequena queda em 2016 e estabilizada em 2017 (Figura 3). No período, com queda mais acentuada, encontra-se a UCPEL, mas, também, sofreram declínio, no ano de 2016, em relação a 2015, PUCSP, PUCRS, UCB e PUC-CAMPINAS, as demais, todas com desempenho ascendente.

\section{Consideraçóes finais}

Neste estudo, verificou-se diferentes metodologias e diferentes critérios para definir a qualidade de uma universidade, dado que cada ranking 
mensura aquilo que compreende como indicadores importantes, corroborando para nosso entendimento sobre a qualidade ser um conceito dinâmico que tem que se adaptar às permanentes mudanças sociais e econômicas (UNESCO, 2001), além disso os Rankintacs operam com diferentes objetivos e conceitos definidos por seus promotores com indicadores com pesos e formas de coleta distintos entre si (CALDERÓN, 2019).-

Se por um lado as Católicas têm a marca da tradição, amparadas pela égide de seus brasóes, os Rankintacs, por sua vez, têm potencialidades para mostrar que existe uma heterogeneidade neste segmento, fato que nos permite afirmar que em tempos de rankings a transparência passa a ser uma característica valorizada, pois traz à luz fragilidades e potencialidades que até então passavam desapercebidas pelo público em geral.

Numa análise mais pontual, comparamos, guardadas as devidas ressalvas, o possível de comparar, onde identificamos algumas disparidades existentes entre as Católicas, observadas nas Figuras 1, 2 e 6, ou seja, numa análise comparativa entre os resultados do RUF, GUIA e IGC, podemos afirmar que ambos são unânimes em classificar PUC-RIO e PUCRS, como universidades de alto desempenho, figurando no grupo de elite das universidades brasileiras. Considerando que o GUIA premia as 20 melhores universidades privadas do país, a PUC GOIÁS, universidade de grande porte, ocupa este grupo de excelência na vigésima posição, colocação suficiente para constar do "Prêmio", no entanto, possui desempenho fraco, tanto no IGC quanto no RUF.

Outro ponto fora da curva, entre as Católicas é a UCSAL, universidade de médio porte, que não alcançou desempenho suficiente para compor o prêmio do GUIA, como também, possui desempenho baixo no IGC e no RUF. A UNICAP, não figura no grupo de excelência do GUIA, porém, possui bom desempenho no RUF e no IGC.

Nas demais Católicas, alguns elementos destoam da regularidade, como por exemplo, entre as Católicas de grande porte, UNISINOS e PUCPR possuem alto desempenho no IGC e descem para o $2^{\circ}$ quartil de bom desempenho no RUF, enquanto, PUC MINAS alcançou bom desempenho no IGC, mas manteve-se no terceiro quartil (regular) no RUF, enquanto, destas três universidades, UNISINOS e PUC MINAS alcançaram nível de excelência no prêmio do GUIA, PUCPR ocupou o segundo quartil com bom desempenho. 
Em relação as Católicas de médio porte, PUCSP tem alto desempenho no IGC e aparece em um quartil abaixo (bom desempenho), no RUF e no GUIA, enquanto UCB inverte o quadro, ou seja, alto desempenho no RUF e no $2^{\circ}$ quartil do IGC com bom desempenho, no entanto, cai para o terceiro quartil, com desempenho regular entre as "melhores universidades" do GUIA. PUC-CAMPINAS e USF destacam-se com bom desempenho no RUF, caem para $3^{\circ}$ quartil do IGC (desempenho regular), porém, enquanto PUC-CAMPINAS destaca-se no prêmio do GUIA com bom desempenho, USF não alcança resultado suficiente para compor este grupo. No caso da UCDB inverte a situação no RUF e IGC, ou seja, desempenho regular no RUF ( $3^{\circ}$ quartil) e bom no IGC e, da mesma forma que USF, também, não alcança desempenho suficiente para estar no prêmio do GUIA.

Já, entre as Católicas de pequeno porte, temos a UCPEL que tem bom desempenho no RUF, no entanto, cai para regular no IGC ( $3^{\circ}$ quartil). Um fato que chama a atenção é que USC e UNISANTOS que possuem alto desempenho no IGC e desempenho regular no RUF descem dois quartis, enquanto UCP aparece com baixo desempenho no RUF, porém, sobe dois quartis e alcança bom desempenho no IGC. Nenhuma Católica de pequeno porte obteve resultado suficiente para compor o "Prêmio Melhores Universidades" do GUIA.

A variabilidade de posições entre as Católicas indica potencialidades em alguns indicadores que são exclusivos de um ou outro ranking, por exemplo, temos o RUF que considera dois aspectos, ensino e mercado, tendo o "mercado" com $36 \%$ do total da nota, que leva em conta, pesquisa de opinião com profissionais de $\mathrm{RH}$, e "ensino" com $64 \%$ da nota, com quatro componentes: avaliadores do MEC (40\%); professores com doutorado e mestrado (8\%); professores em dedicação integral e parcial (8\%) e; nota no ENADE (8\%). Por sua vez, o IGC, é um indicador de "qualidade" do MEC, que leva em conta os aspectos, como: média do CPC do último triênio; média dos conceitos de avaliação dos programas de pós-graduação stricto sensu atribuídos pela CAPES e; distribuição dos estudantes entre os diferentes níveis de ensino, graduação ou pós-graduaçáo stricto sensu. Vale ressaltar que na composição do IGC entra médias que envolvem, também, a participação do aluno e seu desempenho na prova do Enade, fato que pode sugerir o fato de algumas 
IES ter destaque de excelência em alguns rankings, mas fraco desempenho no IGC. Já o "Prêmio Melhores Universidades" do GUIA avalia as universidades a partir de pesquisa de opinião feita, basicamente, com professores e coordenadores de cursos, sob três aspectos: projeto didático-pedagógico, corpo docente e, infraestrutura.

Os Rankintacs exigem uma análise cuidadosa de cada indicador, pois o que é apontado como fraqueza em uma IES, pode ser potencialidade para outra, algumas Católicas são destaques em ensino, outras ricas em pesquisa, outras seguem à risca as diretrizes de carreira docente, respeitando os critérios exigidos pelo MEC de mais de 1/3 em regime de dedicação integral e formado por doutores, outras tem conceito alto em programas de pós-graduação, enfim, existe uma heterogeneidade entre as Católicas identificadas pelos rankings que seguem metodologias distintas entre si. Os dados fornecem elementos para tomada de decisão auxiliando as IES a melhorarem seus resultados na busca pela qualidade.

\section{Notas}

1 Este artigo engloba-se no projeto "Governança universitária em tempos de RANKINTACs (rankings acadêmicos, índices e tabelas classificatórias) nas instituiçôes de educação superior brasileiras" (Processo no 311333/2017-6), coordenado pelo Dr. Adolfo Ignácio Calderón, Bolsista Produtividade em Pesquisa do Conselho Nacional de Desenvolvimento Científico e Tecnológico (CNPq).

2 Em 2006, o IREG Observatory, composto por agências que produzem rankings e por alguns especialistas de universidades, produziu uma lista de princípios para a produção e a interpretação responsável de rankings universitários, destacando a importância da transparência metodológi$\mathrm{ca}$, do respeito para a diversidade em missão e modelo de universidade.

3 Censo do Ensino Superior INEP-MEC (2016), ENADE (2014, 2015 e 2016), SciELO (20112015), Web of Science (2011-2015 e 2016 para citaçôes), INPI (2007-2016), CAPES (2016), CNPq (2016), Fundaçóes estaduais de fomento à ciência (2016) e pesquisas de opiniáo Datafolha (2016, 2017 e 2018).

4 O Prêmio "Guia do Estudante" - Destaques do Ano 2015, que integra os Prêmios Santander Universidades (santanderuniversidades.com.br/premios), reconhece as instituiçóes de Ensino Superior (IES) que mais se destacaram nos últimos 12 meses.

5 1) Consultoria técnica: O GUIA conta com estatísticos que prestam consultoria técnica na sistematização e análise de dados. 2) Estrelados x não estrelados: Todos os cursos que passaram pela avaliação obtêm um conceito, mas somente são divulgados aqueles que conquistaram 3 , 4 ou 5 estrelas (só estes são considerados estrelados). 3) Limites das faixas: A nota máxima e mínima de cada uma das faixas de estrelas săo determinadas pelo desvio padrăo, que leva em conta o desempenho do conjunto de cursos e o quanto as notas variaram em relação à média naquele ano. 4) A imagem do curso: Vale lembrar que, por se tratar de uma pesquisa de opiniāo, os resultados refletem, sobretudo, a imagem que o curso tem perante a comunidade acadêmica (reitores, diretores, coordenadores e professores). 
6 Concorrem somente as escolas que tiveram, no mínimo, dois cursos estrelados (3, 4 e 5 estrelas) na área em questáo. As vencedoras foram aquelas cujas graduaçóes conseguiram melhor desempenho na avaliação, na área considerada.

\section{Referências}

ALTBACH, Philip G.; HAZELKORN, Ellen. Por que os rankings falham ao medir a qualidade da educação. Desafios da Educação. 2018. Disponível em: https:// desafiosdaeducacao.com.br/qualidade-educac\%CC \%A7a\%CC \%83o-rankings-globais/. Acesso em: 26/07/2019

ARDUINI, Guilherme Ramalho. A Igreja Católica e suas instituiçóes de Ensino Superior. Pro-Posiçôes. v. 28, n. 3 (84), Set/Dez. 2017. http://dx.doi.org/10.1590/19806248-2016-0107

\section{BRASIL, INSTITUTO NACIONAL DE ESTUDOS E PESQUISAS} EDUCACIONAIS ANÍSIO TEIXEIRA (2017a). Censo da Educação Superior 2017: Principais Resultados. Disponível em: <http://download.inep.gov.br/ informacoes_estatisticas/sinopses_estatisticas/sinopses_educacao_superior/ sinopse_educacao_superior_2017.zip>. Acesso em: 22/02/2019.

\section{BRASIL, INSTITUTO NACIONAL DE ESTUDOS E PESQUISAS} EDUCACIONAIS ANÍSIO TEIXEIRA. Índice Geral de Cursos (IGC). Disponível em: http://inep.gov.br/indice-geral-de-cursos-igc-. (Página atualizada em: 20 outubro de 2015). Acesso em: 05/01/2019.

BRASIL, MINISTÉRIO DA EDUCAÇÃO (e-MEC) (2018). Instituições de Educação Superior e Cursos Cadastrados. Disponível em: http://emec.mec.gov.br/. Acesso em: 05/11/2018.

\section{BRASIL, MINISTÉRIO DA EDUCAÇÃO. Bases para uma Nova Proposta de} Avaliação da Educação Superior. 2003. Disponível em: http://portal.mec.gov.br/ arquivos/pdf/sinaes.pdf. Acesso em: 25/05/2019.

CALDERÓN, Adolfo Ignácio, Professor pesquisador da PUC-Campinas passa a integrar o quadro de avaliadores da Área de Educação CAPES. Entrevista concedida ao Jornal da PUC-Campinas, Edição 191 - Ano 2019. Disponível em: http://jornal. puc-campinas.edu.br/professor-pesquisador-da-puc-campinas-passa-a-integrar-oquadro-de-avaliadores-da-area-de-educacao-capes/. Acesso em: 25/07/2019

CALDERON, Adolfo Ignacio. Universidades mercantis: a institucionalização do mercado universitário em questão. São Paulo Perspectiva, São Paulo, v. 14, n. 1, p. 61-72, Mar. 2000. http://dx.doi.org/10.1590/S0102-88392000000100007. 
CALDERON, Adolfo Ignácio; POLTRONIERI, Heloisa; BORGES, Regilson Maciel. Os rankings na educaçáo superior brasileira: políticas de governo ou de Estado? Ensaio: aval. pol. públ. Educ., Rio de Janeiro, v. 19, n. 73, p. 813-826, out./dez. 2011.

DEMING, William Edwards. Qualidade: a revoluçâo da administração. Rio de janeiro: Marques Saraiva, 1990

DEMO, Pedro. Educação e Qualidade. Campinas: Papirus, 1994.

FEIJOO, AMLC. 6. Medidas separatrizes. In: A pesquisa e a estatística na psicologia e na educação [online]. Rio de Janeiro: Centro Edelstein de Pesquisas Sociais, 2010

FERNANDES, Fernando José Anjos Silva Vaz. Representação das Universidades Portuguesas através dos Rankings Universitários Internacionais (ARWU, QS e THE): validade, representação e posicionamento. 2015. Dissertação (Mestrado Informação, Comunicação e Novos Media). Universidade de Coimbra.

GANGA-CONTRERAS, Francisco Aníbal; SAN MARTÍN, Walter Sáez; RODRÍGUEZ-PONCE, Emilio; CALDERÓN, Adolfo-Ignacio; WANDERCIL, Marco. Universidades Públicas de Chile y su Desempeño en los Rankings Académicos Nacionales. Fronteiras: Journal of Social, Technological and Environmental Science. v. 7, n. 3, p. 316-341, set./dez. 2018. DOI http://dx.doi.org/10.21664/2238-8869.2018v7i3. p316-341

GENTILI, Pablo. O discurso da qualidade como nova retórica conservadora no campo educacional. In GENTILI, Pablo e SILVA, Tomaz Tadeu (orgs.). Neoliberalismo, qualidade total e educação: visóes críticas. $3^{\text {a }}$ ed; Petrópolis: Vozes, 1995

GUIA DO ESTUDANTE PROFISSÓES VESTIBULAR 2015. Saiba como encontrar o Curso Superior ideal para você. Sáo Paulo: Editora Abril. 2014.

GUIA DO ESTUDANTE PROFISSÓES VESTIBULAR 2016. Encontre o Curso Superior que mais combina com você. São Paulo: Editora Abril. 2015.

GUIA DO ESTUDANTE PROFISSÓES VESTIBULAR 2017. Opçóes de Cursos Superiores para você escolher. São Paulo: Editora Abril. 2016.

GUIA DO ESTUDANTE PROFISSŌES VESTIBULAR 2018. Opçôes de Carreira para você escolher. São Paulo: Editora Abril. 2017.

GUIA DO ESTUDANTE PROFISSÓES VESTIBULAR 2019. Opçóes de Carreira para você escolher. São Paulo: Editora Abril. 2018.

IREG (International Ranking Expert Group). Principios de Berlin para Rankings de Instituiçôes de Educação Superior. Berlin, 20 de maio de 2006. Disponível em: http:// ireg-observatory.org/en/berlin-principles-portuguese. Acesso em: 24/07/2019

ISHIKAWA, Karou. Controle de qualidade total: à maneira japonesa. Rio de Janeiro: Campus, 1993 
LEVA, José Ulisses. PUC SP - Identidade Católica da Universidade. Revista Eletrônica Espaço Teológico ISSN 2177-952X. v. 10, n. 17, p. 07-16, jan/jun, 2016.

LOURENÇO, Henrique da Silva. Os rankings do guia do estudante na educação superior brasileira: um estudo sobre as estratégias de divulgaçâo adotadas pelas instituiçóes que obtiveram o prêmio melhores universidades. 2014. 205f. Dissertaçáo de Mestrado - Gestão e Políticas Públicas em Educação, Pontifícia Universidade Católica de Campinas, Campinas, 2014.

MARTINS, Carlos Benedito. Privatização: A Política do Estado Autoritário para o Ensino Superior. In: Cadernos CEDES. Campinas: Papirus, (5), pp: 43-61, 1987.

ORDORIKA, I.; RODRIGUEZ GOMEZ, R. El ranking Times en el mercado del prestigio universitario. Perfiles Educativos, Distrito Federal, México, v. 32, n. 129, jan. 2010.

RIGHETTI, S. Qual é a melhor? Origem, indicadores, limitaçóes e impactos dos rankings universitários. 2016. Tese (Doutorado em Política Científica e Tecnológica) Universidade Estadual de Campinas.

RUF. Ranking Universitário Folha. Rankings de Universidades. 2018. Disponível em http://ruf.folha.uol.com.br/2018/. Acesso em: 22/10/2018.

SANTANA, Flávia Feitosa. A dinâmica da aplicação do termo qualidade na educação superior brasileira. São Paulo: Editora Senac São Paulo, 2007

SANTOS, Solange Maria dos; NORONHA, Daisy Pires. O desempenho das universidades brasileiras em rankings internacionais. Em Questäo, Porto Alegre, v. 22, n. 2, p. 186-219, mai/ago. 2016. DOI: 10.19132/1808-5245222.186-219

UNESCO, 2001. "Los países de América Latina y el Caribe adoptan la declaración de Cochabamba sobre educación”. In: Anais da Oficina de información Pública para América Latina y Caribe. Disponível em: http:www.iesalc.org. Acesso em: 04/2019

WEST, Josie; MATTIS, George; PHILIPPOU, Georgia. Demystifying the Rankings: A Guide for Universities. Disponível em: http://info.qs.com/rs/335-VIN-535/images/ Demstyifying\%20the\%20Rankings\%20White\%20Paper.pdf. Acesso: 24/05/2019.

Recebido em 5 ago. 20I9 / Aprovado em I7 dez. 2019

Para referenciar este texto:

WANDERCIL, M.; CALDERÓN, A. I.; CONTRERAS, F. A. G. Qualidade da educação superior no Brasil: desempenho das universidades católicas à luz dos rankings acadêmicos, índices e tabelas classificatórias estatais e do setor privado. EccoS - Revista Científica, São Paulo, n. 5I, eI458I, out./dez. 2019. Disponível em: https://doi.org/I0.5585/EccoS.n50.I458I. 